\title{
Cross-Sectional and Time-Series Momentum Returns and Market States
}

\begin{abstract}
Recent evidence on momentum returns shows that the time-series (TS) strategy outperforms the cross-sectional (CS) strategy. We present new evidence that this happens only when the market continues in the same state, UP or DOWN. In fact, we find that the TS strategy underperforms the CS strategy when the market transitions to a different state. Our results also show that the difference in momentum returns between TS and CS strategies is related to both the net long and net short positions of the TS strategy.

JEL Codes: G11, G12, G14
\end{abstract}

\section{INTRODUCTION}

Momentum trading strategies rely on return predictability based on past returns with much of the early momentum literature dealing with cross-sectional patterns, in line with studies that investigate asset pricing anomalies. For example, Jegadeesh and Titman (1993) show that stocks that have outperformed (underperformed) their peers in the past three to 12 months usually continue to outperform (underperform) in the next three to 12 months. This has led to the so called cross-sectional momentum strategy of buying recent winners and short-selling recent losers relative to the cross-section of stocks. The cross-sectional momentum strategy has subsequently been shown to be profitable in several asset classes and markets (e.g. Rouwenhorst, 1998, Asness, Moskowitz and Pedersen, 2013). ${ }^{1}$ More recently, Moskowitz, Ooi and Pedersen (2012) document a 'time-series or trend momentum' and show that a momentum strategy that buys and sells certain assets based only on their own past performance (not relative to their peers) is also profitable. ${ }^{2}$ They document persistence in

\footnotetext{
${ }^{1}$ Momentum profits are apparently conditioned by business cycles (Chordia and Shivakumar, 2002), market states and market dynamics (Cooper, Gutierrez and Hameed, 2004, Asem and Tian, 2010), and market volatility (Wang and $\mathrm{Xu}, 2015$ ). Daniel and Moskowitz (2016) show that momentum strategies can also experience infrequent bouts of negative returns which are partly forecastable.

${ }^{2} \mathrm{He}$ and $\mathrm{Li}$ (2015) propose a continuous-time model consisting of fundamental, momentum and contrarian traders to explain time-series momentum. They show that the performance of the time-series momentum
} 
returns of a large set of futures and forward contracts for one to 12 months which has led to the so called time-series momentum strategy of buying (selling) the asset if its excess returns in the previous $k$ months are positive (negative). The time-series momentum strategy is closely related to the extensive technical trading literature. ${ }^{3}$

Recent evidence on momentum returns suggests that the time-series (TS) strategy proposed by Moskowitz et al. (2012) outperforms the cross-sectional (CS) strategy of Jegadeesh and Titman (1993) because of its stock selection abilities (e.g. Asness et al., 2013). However, Goyal and Jegadeesh (2015) show that the TS strategy outperforms the CS because of the compensation of its net long position instead of its stock selection abilities. They argue that TS is a combination of a zero-net investment strategy and a net long investment in the risky assets, whereas CS is an entirely zero-cost strategy. Therefore, the compensation of the net long investment in risky assets enhances the performance of the TS strategy, which not only earns the risk premium relative to the CS strategy but also benefits from market timing because there are more up than down markets.

In this paper, we empirically examine whether the TS strategy outperforms the CS strategy because of its net long position by conditioning momentum returns on market states. Following Asem and Tian (2010), at the beginning of each month $t+1$, we define market states based on lagged 12-month (t-11 to t) and subsequent month (t+1) Centre for Research

\footnotetext{
strategy depends on both the time horizon and the market dominance of momentum traders. Meanwhile Berghorn (2015) suggest that trends are more prevalent in the real world than in theory and that the exploitation of these trends could be important to investment success.

${ }^{3}$ The profitability of these technical trading rules has been documented in several studies including Neftci (1991), Levich and Thomas (1993), Brock, Lakonishok and LeBaron (1992), Neely, Weller and Dittmar (1997), Allen and Karjalainen (1999), Gencay (1998a) and Gencay (1999). Studies have also shown evidence of nonlinear predictability in stock returns using past buy and sell signals of simple technical trading rules that are closely related to time-series momentum strategies such as moving averages (e.g. Gencay, 1996, Gencay, 1998b, Gencay and Stengos, 1997, Gencay and Stengos, 1998). More recently Gradojevic and Gençay (2013) propose that the use of fuzzy logic could reduce the twin uncertainties associated with technical trading strategies, that of market timing and order size. They show that 'fuzzy logic technical indicators' dominate standard moving average indicators and filter rules. Gradojevic and Lento (2015) also show that the activities of technical traders can be such that they result in violations of the assumption that exchange rate movements are driven by order flow. In an earlier study, Arifovic and Gencay (2000) show in a genetic learning model that the profit seeking behaviour of genetic algorithm agents results in chaotic patterns in exchange rate returns.
} 
in Security Prices (CRSP) value-weighted market returns. ${ }^{4}$ A market state is identified as UP/UP (DN/DN) when the lagged, and subsequent market returns are both positive (negative). We classify the market state as UP/DN (DN/UP) if the lagged 12-month returns are positive (negative) and the subsequent market returns are negative (positive).

To the extent that momentum returns of the TS strategy exceed the CS strategy because of its net long position as suggested by Goyal and Jegadeesh (2015), then TS momentum returns would be relatively higher in the UP/UP market because the net long position would time the subsequent UP market. However, if TS momentum returns exceed the CS because of its active position whether net long or net short, then we should expect relatively higher TS momentum returns in market continuations whether UP/UP or DN/DN because the net long (net short) position times the subsequent UP (DN) market. Furthermore, we expect that the TS strategy would underperform the CS strategy in market transitions (UP/DN or DN/UP) because the net long (short) position of the TS strategy negatively times the subsequent DN (UP) market.

Consistent with our expectations, we find that the TS strategy outperforms (underperforms) the CS strategy only in market continuations (transitions). We find that the net long/short position times the market in market continuations thereby enhancing TS momentum returns. However, in market transitions, the net long/short position exhibit negative autocorrelation with the subsequent market returns which results into larger losses for the TS strategy.

Our study makes two important contributions to the existing momentum literature. First, it presents new evidence that the TS strategy outperforms the CS strategy only in market continuations as it underperforms in market transitions. Second, it extends the earlier work of

\footnotetext{
${ }^{4}$ Our results remain similar if we define market states based on lagged 36-, 24- and 6-month market returns. Furthermore, our results remain similar if we define market states (bull versus bear) based on technical indicators e.g., moving average using S\&P500 Composite Index, CRSP Value-Weighted Market Index and Dow Jones Industrial Index. These results are available upon request.
} 
Goyal and Jegadeesh (2015) by showing that the difference between TS and CS momentum returns is not only related to the net long but also to the net short position of the TS strategy. The paper is organized as follows: Section II describes the data and methods, Section III presents the empirical results and the last section concludes.

\section{DATA AND METHODS}

We collect monthly returns and market capitalization data of all the common stocks in the CRSP database during the period January 1946 to December $2015 .{ }^{5}$ Following the literature (e.g. Goyal and Jegadeesh, 2015), we exclude stocks that are below the $20^{\text {th }}$ percentile of NYSE market capitalization at the portfolio formation date.

At the beginning of each month $\mathrm{t}+1$, we sort stocks into two portfolios (losers and winners) based on their lagged 6-month (t-6 to t-1) returns, skipping month t to mitigate the bid-ask bounce effect. We hold these portfolios for the next six months, $t+1$ to $t+6$. We rebalance portfolios monthly, as in Jegadeesh and Titman (1993).

For the TS strategy, we buy (sell) stocks with returns higher (lower) than the risk-free rate. The momentum returns for the TS strategy are the sum of the first and third terms less the second and fourth terms, as shown below. ${ }^{6}$

$$
\operatorname{TS}\left(\mathrm{MOM}_{t}\right)=\frac{1}{N^{+}} \sum_{R_{i t-1} \geq 0} R_{i t}-\frac{1}{N^{-}} \sum_{R_{i t-1}<0} R_{i t}+\text { Net Long } \cdot 1_{N^{+}>N^{-}}-\text {Net Short } \cdot 1_{N^{-}>N^{+}}
$$

$T S\left(M O M_{t}\right)$ is the momentum returns for the TS strategy for month t. The first and second terms show the average monthly excess returns of winners' and losers' portfolios. The third and fourth terms show the average monthly excess returns of the net long and net short positions when the number of stocks in winners' and losers' portfolios are not equal. The net

\footnotetext{
${ }^{5}$ Our results remain qualitatively similar whether we use monthly or daily returns to construct and hold momentum portfolios.

${ }^{6}$ Our TS estimation approach is a bit different from the one mentioned in equation 2 of Goyal and Jegadeesh (2015). They multiply the difference of long and short position by two and then divide it by the total number of stocks to ensure that TS strategy is comparable to the CS strategy. However, their approach results in higher momentum profits or losses once we condition TS momentum returns on market states because a larger long (short) position following UP (DN) market is multiplied by two which could enhance momentum profits/losses conditioned on market states. Nonetheless, we also compute TS momentum returns based on the approach mentioned in their paper, and our findings remain robust. These results are available upon request.
} 
long (short) position will be equal to zero if the number of buy (sell) stocks is less than sell (buy) stocks. The average monthly returns of the net long and net short position are shown below in equations 2 and 3.

$$
\begin{aligned}
& \text { Net Long }=\frac{\left(N^{+}-N^{-}\right)}{\left(N^{+}\right)} \sum_{R_{i t-1} \geq R_{t-1}} R_{i t} \\
& \text { Net Short }=\frac{\left(N^{-}-N^{+}\right)}{\left(N^{-}\right)} \sum_{R_{i t-1}<R_{t-1}} R_{i t}
\end{aligned}
$$

For the CS strategy, we buy (sell) stocks with returns greater (lower) than the crosssectional average. As in Goyal and Jegadeesh (2015), we calculate CS momentum returns as the difference of the excess returns between buy and sell portfolios as shown below. ${ }^{7}$

$$
\operatorname{CS}\left(M O M_{t}\right)=\frac{1}{N^{+}} \sum_{R_{i t-1} \geq R_{t-1}} R_{i t}-\frac{1}{N^{-}} \sum_{R_{i t-1}<R_{t-1}} R_{i t}
$$

$C S\left(M O M_{t}\right)$ is the CS momentum returns for month $\mathrm{t}, R_{i t-1}$ is the formation period return of stock $i$, and $R_{t-1}$ is the cross-sectional average of the formation period returns. $N^{+}\left(N^{-}\right)$ is the number of stocks with returns greater (lower) than the cross-sectional average formation period returns. The CS is a zero-cost strategy that invests an equal amount in buy and sell portfolios.

We also estimate the risk-adjusted momentum returns (Alpha) of the CS and TS strategies. First, we obtain the factor loadings $(\beta)$ by regressing the TS and CS momentum returns on the (CAPM and FF) risk factors and a constant. ${ }^{8}$ The risk-adjusted momentum returns of each month are

$$
M R_{t}^{a d j}=M R_{t}-\sum \beta_{i} f_{i t}
$$

where $M R_{t}$ is the momentum return for month $t, f_{i t}$ is the realization of factor $i$ in month $t$, and $\beta_{i}$ is the estimated factor loading obtained from the regression.

\section{EMPIRICAL FINDINGS}

\footnotetext{
${ }^{7}$ The excess returns for the CS strategies are equal to the raw returns because both winners' and losers' portfolios take equal positions in stocks.

${ }^{8}$ We collect data on risk factors from Professor Kenneth R. French's library.
} 
Table 1 presents the descriptive statistics of excess returns of the TS and CS momentum portfolios. We find unconditional TS (CS) momentum returns of $0.62 \%(0.36 \%)$ per month. The difference in unconditional momentum returns between TS and CS strategies at $0.26 \%$ is statistically significant $(t$-statistics $=3.12)$. The excess market returns are $0.62 \%$ per month which are equal to the unconditional TS momentum returns but higher than the unconditional CS momentum returns. ${ }^{9}$

\section{[Table 1 about here]}

Table 1 also shows that the TS (CS) momentum returns are negatively skewed with a skewness coefficient of -2.24 (-1.06). Furthermore, TS (CS) momentum returns have a high excess kurtosis of 10.97 (11.56). The high negative skewness and high excess kurtosis of TS and CS momentum returns imply a significant crash risk.

Table 2 reports TS and CS momentum returns conditioned on market states, the difference in momentum returns between TS and CS strategies, and the difference in returns of both TS and CS strategies from the buy-and-hold (BH) strategy. ${ }^{10} \mathrm{We}$ find four patterns from Table 2. Firstly, both the TS and CS momentum strategies are profitable only when the market continues in the same state. ${ }^{11}$ For example, TS momentum returns are $1.81 \%(3.19 \%)$ per month and CS momentum returns are $0.70 \%$ (1.57\%) per month when the market is in the UP/UP (DN/DN) state. ${ }^{12}$ However, the TS strategy loses when the market transitions to another state. For example, TS momentum returns are $-0.83 \%(-2.85 \%)$ per month in the

\footnotetext{
${ }^{9}$ Note that our unconditional CS momentum returns ( $0.36 \%$ per month) appear to be weaker than the excess market returns $(0.62 \%)$. This is because we follow Goyal and Jegadeesh (2015) and employ only two portfolios each for the CS and TS strategies to make them directly comparable (since our main intention in this paper is to compare the CS and TS strategies). However, if we use decile portfolios to execute the CS strategy as normally done in the literature, the unconditional CS momentum returns are $1.03 \%$ per month and the difference of $0.41 \%$ per month from the market return of $0.62 \%$ is statistically significant.

${ }^{10}$ We use excess market returns for the buy-and-hold strategy since both CS and TS momentum returns are also based on excess returns.

11 The positive and significant CS momentum returns in market continuations are consistent with Asem and Tian (2010).

${ }^{12}$ Following the estimation approach as in Goyal and Jegadeesh (2015), we find TS momentum returns of $2.28 \%,-1.79 \%,-3.72 \%$ and $3.63 \%$ per month in UP/UP, UP/DN, DN/UP and DN/DN market states, respectively.
} 
UP/DN (DN/UP) market state. The CS strategy also loses when the market transitions to the UP (DN/UP) state, losing $-1.12 \%$ per month. However, CS momentum returns are only $0.01 \%$ per month in the UP/DN market state.

\section{[Table 2 about here]}

Secondly, the TS strategy outperforms (underperforms) the CS strategy in market continuations (transitions). For example, the TS strategy earns 1.12\% (1.62\%) higher returns than the CS strategy in the UP/UP (DN/DN) market. However, UP/DN (DN/UP) market states result in $0.84 \%(1.73 \%)$ lower returns for the TS strategy compared to the CS strategy. Furthermore, the higher (lower) Sharpe ratio of the TS momentum returns compared to the CS momentum returns in market continuations (transitions) provide further evidence that the TS strategy outperforms (underperforms) the CS strategy in market continuations (transitions).

Thirdly, we find that the difference in momentum returns between the TS and CS strategies arise from either the net long or net short position of the TS strategy as the TS strategy takes a net long (short) position following UP (DN) markets. For example, in untabulated results, the TS strategy takes a net long position for 510 out of 643 months following the UP market state (UP/UP, UP/DN), while it takes a net short position for 122 out of 185 months following DOWN market states (DN/UP, DN/DN). Therefore, the net long (short) position times the market in the UP/UP (DN/DN) market state which enhances the profitability of the TS strategy. However, market transitions such as UP/DN (DN/UP) exhibit a negative autocorrelation with the net long (short) position which results in lower returns for the TS strategy relative to the CS strategy. Furthermore, the average monthly returns of the "winners-minus-losers" (W-L) show that the difference between the TS and CS strategies is small after the exclusion of the net long and net short positions. 
Lastly, we find that the BH strategy outperforms the TS and CS momentum strategies in the UP/UP and DN/UP market states; whereas, the BH strategy underperforms the TS and CS momentum strategies in the UP/DN and DN/DN state. For example, the BH strategy earns $1.09 \%$ (2.21\%) per month higher returns than the TS (CS) strategy in the UP/UP state and $7.00 \%(5.27 \%)$ per month higher returns than the TS (CS) strategy in the DN/UP state. However, the BH strategy earns $2.38 \%$ (3.22\%) per month lower returns than the TS (CS) strategy in the UP/DN state and $7.80 \%(6.17 \%)$ per month lower returns than the TS (CS) strategy in the DN/DN state. Since BH is a long only strategy, it has a strong positive (negative) autocorrelation with subsequent UP (DN) market and earns relatively higher (lower) returns when the subsequent market is UP (DN). Furthermore, a short only strategy should earn relatively higher (lower) returns when the subsequent market is DN (UP). In sum, the long or net long (short or net short) position earns higher returns when the subsequent market is UP (DN). This provides further evidence as to why the TS strategy outperforms (underperforms) the CS strategy in market continuations (transitions) since the TS strategy takes an active position which has a positive (negative) autocorrelation with the subsequent market.

\section{CONCLUDING REMARKS}

In this paper we examine the impact of market states on the momentum returns of the TS and CS strategies. Our findings show that both strategies are profitable only in market continuations. We also find that the TS strategy outperforms (underperforms) the CS in market continuations (transitions). In contrast to the existing evidence that the key difference between TS and CS momentum returns is related to the net long position, our results show that the key difference between TS and CS momentum returns depends not only on the net long but also on the net short position. 


\section{References}

Allen, F. and R. Karjalainen (1999), 'Using genetic algorithms to find technical trading rules', Journal of Financial Economics, 51, 245-71.

Arifovic, J. and R. Gencay (2000), 'Statistical properties of genetic learning in a model of exchange rate', Journal of Economic Dynamics and Control, 24, 981-1005.

Asem, E. and G. Y. Tian (2010), 'Market dynamics and momentum profits', Journal of Financial and Quantitative Analysis, 45, 1549-62.

Asness, C. S., T. J. Moskowitz and L. H. Pedersen (2013), 'Value and momentum everywhere', The Journal of Finance, 68, 929-85.

Berghorn, W. (2015), 'Trend momentum', Quantitative Finance, 15, 261-84.

Brock, W., J. Lakonishok and B. Lebaron (1992), 'Simple technical trading rules and the stochastic properties of stock returns', The Journal of Finance, 47, 1731-64.

Chordia, T. and L. Shivakumar (2002), 'Momentum, business cycle, and time-varying expected returns', The Journal of Finance, 57, 985-1019.

Cooper, M. J., R. C. Gutierrez and A. Hameed (2004), 'Market states and momentum', The Journal of Finance, 59, 1345-65.

Daniel, K. and T. J. Moskowitz (2016), 'Momentum crashes', Journal of Financial Economics, 122, 221-47.

Gencay, R. (1996), 'Non-linear prediction of security returns with moving average rules', Journal of Forecasting, 15, 165-74.

Gencay, R. (1998a), 'Optimization of technical trading strategies and the profitability in security markets', Economics Letters, 59, 249-54.

Gencay, R. (1998b), 'The predictability of security returns with simple technical trading rules', Journal of Empirical Finance, 5, 347-59.

Gencay, R. (1999), 'Linear, non-linear and essential foreign exchange rate prediction with simple technical trading rules', Journal of International Economics, 47, 91-107.

Gencay, R. and T. Stengos (1997), 'Technical trading rules and the size of the risk premium in security returns', Studies in Nonlinear Dynamics and Econometrics, 2, 23-34.

Gencay, R. and T. Stengos (1998), 'Moving average rules, volume and the predictability of security returns with feedforward networks', Journal of Forecasting, 17, 401-14.

Goyal, A. and N. Jegadeesh (2015), 'Cross-Sectional and Time-Series Tests of Return Predictability: What is the Difference?', Available at SSRN 2610288. 
Gradojevic, N. and R. Gençay (2013), 'Fuzzy logic, trading uncertainty and technical trading', Journal of Banking \& Finance, 37, 578-86.

Gradojevic, N. and C. Lento (2015), 'Multiscale analysis of foreign exchange order flows and technical trading profitability', Economic Modelling, 47, 156-65.

He, X.-Z. and K. Li (2015), 'Profitability of time series momentum', Journal of Banking \& Finance, 53, 140-57.

Jegadeesh, N. and S. Titman (1993), 'Returns to buying winners and selling losers: Implications for stock market efficiency', The Journal of Finance, 48, 65-91.

Levich, R. M. and L. R. Thomas (1993), 'The significance of technical trading-rule profits in the foreign exchange market: a bootstrap approach', Journal of International Money and finance, $12,451-74$.

Moskowitz, T. J., Y. H. Ooi and L. H. Pedersen (2012), 'Time series momentum', Journal of Financial Economics, 104, 228-50.

Neely, C., P. Weller and R. Dittmar (1997), 'Is technical analysis in the foreign exchange market profitable? A genetic programming approach', Journal of Financial and Quantitative Analysis, 32, 405-26.

Neftci, S. N. (1991), 'Naive trading rules in financial markets and wiener-kolmogorov prediction theory: a study of" technical analysis"', Journal of Business, 549-71.

Rouwenhorst, K. G. (1998), 'International momentum strategies', The Journal of Finance, 53, 267-84.

Wang, K. Q. and J. Xu (2015), 'Market volatility and momentum', Journal of Empirical Finance, 30, 79-91. 


\section{Table 1: Time-series and cross-sectional momentum portfolios characteristics}

This table reports the descriptive statistics of excess returns of the TS and CS momentum portfolios. At the beginning of each month $t+1$, we buy (sell) stocks with positive (negative) excess returns over the risk-free rate in the previous 6 months ( $t-6$ to $t-1$ ) for the TS strategy. For the CS strategy, we buy (sell) stocks above (below) the cross-sectional average based on their lagged 6-month ( $t-6$ to $t-1)$ returns. The CS and TS portfolios are held for 6 months ( $t+1$ to $t+6)$. Panel A reports the average monthly excess returns (r-rf), $t$-statistics of r-rf, minimum, maximum, standard deviation (SD), skewness and kurtosis of the losers (L), winners (W), net long (NL), net short (NS), momentum (MOM) and market (MKT) portfolios of the TS strategy. Panel B reports the average monthly excess returns (r-rf), $t$-statistics of r-rf, minimum, maximum, standard deviation (SD), skewness and kurtosis of the losers, winners, momentum and market portfolios of the CS strategy. For all portfolios except MOM, skewness represents the full-period skewness of the monthly log returns to the portfolios. For CS and TS momentum portfolios, skewness denotes the skewness of $\log (1+\mathrm{MOM}+\mathrm{RF})$. The sample period is from January 1946 to December 2015.

\begin{tabular}{|c|c|c|c|c|c|c|}
\hline \multicolumn{7}{|c|}{ Panel A: Time-Series momentum portfolios } \\
\hline Variables & $\mathrm{L}$ & $\mathrm{W}$ & NL & NS & MOM & MKT \\
\hline r-rf & 0.44 & 0.89 & 0.45 & 0.28 & 0.62 & 0.62 \\
\hline$t(\mathrm{r}-\mathrm{rf})$ & $(2.44)$ & $(5.25)$ & $(5.41)$ & $(3.55)$ & $(4.47)$ & $(4.21)$ \\
\hline Minimum & -24.26 & -28.60 & -17.53 & -13.73 & -30.26 & -23.24 \\
\hline Maximum & 23.42 & 17.26 & 10.35 & 20.04 & 19.01 & 16.10 \\
\hline SD & 5.24 & 4.89 & 2.38 & 2.28 & 3.95 & 4.26 \\
\hline Skewness & -0.28 & -0.68 & -0.75 & 1.37 & -2.24 & -0.53 \\
\hline Kurtosis & 1.90 & 2.66 & 5.61 & 13.45 & 10.97 & 1.85 \\
\hline \multicolumn{7}{|c|}{ Panel B: Cross-Sectional momentum portfolios } \\
\hline Variables & & & $\mathrm{W}$ & & & MKT \\
\hline r-rf & & & 0.93 & & & 0.62 \\
\hline$t(\mathrm{r}-\mathrm{rf})$ & & & $(5.29)$ & & & $(4.21)$ \\
\hline Minimum & & & -29.96 & & & -23.24 \\
\hline Maximum & & & 18.65 & & & 16.10 \\
\hline SD & & & 5.05 & & & 4.26 \\
\hline Skewness & & & -0.66 & & & -0.53 \\
\hline Kurtosis & & & 2.69 & & & 1.85 \\
\hline
\end{tabular}




\section{Table 2: Time-series (TS) and cross-sectional (CS) momentum returns conditioned on market states}

This table reports momentum returns conditioned on lagged and subsequent market states. We define market states based on lagged 12-month ( $t$-11 to $t$ ) and subsequent month $(t+1)$ CRSP value-weighted market returns. At the beginning of each month $t+1$, we classify market states as UP/UP (DN/DN) where lagged and subsequent market returns are both positive (negative). We classify market states as UP/DN (DN/UP) if the lagged market return is positive (negative) and subsequent market return is negative (positive). At the beginning of each month $t+1$, we buy (sell) stocks with positive (negative) excess returns over the risk-free rate in the previous 6 months ( $t$ - 6 to $t$-1) for the TS strategy. For the CS strategy, we buy (sell) stocks above (below) the cross-sectional average based on their lagged 6-month ( $t$ - 6 to $t$-1) returns. The TS and CS portfolios are held for 6 months $(t+1$ to $t+6)$. The table reports the average monthly returns of the losers (L), winners (W), net long (NL), net short (NS), winners-minus-losers (W-L), momentum (MOM), CAPM and Fama-French (FF) alphas, buy-and-hold returns (BH) and the difference in MOM and BH (MOM-BH) returns with $t$-statistics in parentheses. The last column shows the annualized Sharpe ratio (SR). The sample period is from January 1946 to December 2015.

\begin{tabular}{|c|c|c|c|c|c|c|c|c|c|c|c|c|}
\hline \multicolumn{13}{|c|}{ Time-series (TS) and cross-sectional (CS) momentum returns and market states } \\
\hline Market & Strategy & $\mathrm{L}$ & $\mathrm{W}$ & NL & NS & W-L & MOM & CAPM & FF & $\mathrm{BH}$ & MOM-BH & SR \\
\hline \multirow{5}{*}{$\begin{array}{c}\text { UP/UP } \\
(\mathrm{N}=411)\end{array}$} & TS & $\begin{array}{c}2.69 \\
(17.47)\end{array}$ & $\begin{array}{c}3.33 \\
(22.98)\end{array}$ & $\begin{array}{c}1.77 \\
(20.64)\end{array}$ & $\begin{array}{c}0.59 \\
(9.22)\end{array}$ & $\begin{array}{c}0.64 \\
(7.45)\end{array}$ & $\begin{array}{c}1.81 \\
(14.05)\end{array}$ & $\begin{array}{c}1.74 \\
(13.53)\end{array}$ & $\begin{array}{c}1.82 \\
(14.33)\end{array}$ & $\begin{array}{c}2.90 \\
(25.26)\end{array}$ & $\begin{array}{c}-1.09 \\
(-7.29)\end{array}$ & 2.40 \\
\hline & $\mathrm{CC}$ & 2.77 & 3.46 & & & 0.70 & 0.70 & 0.78 & 0.87 & & -2.21 & 1.44 \\
\hline & CS & (19.01) & $(22.78)$ & & & $(8.41)$ & $(8.41)$ & $(9.45)$ & (11.23) & & $(-16.20)$ & \\
\hline & & & & & & -0.06 & 1.12 & 0.96 & 0.95 & & & \\
\hline & TS-CS & & & & & $(-1.74)$ & (14.77) & (12.92) & (12.82) & & & \\
\hline \multirow{4}{*}{$\begin{array}{c}\text { UP/DN } \\
(\mathrm{N}=232)\end{array}$} & TS & $\begin{array}{c}-3.62 \\
(-14.78)\end{array}$ & $\begin{array}{c}-3.23 \\
(-12.20)\end{array}$ & $\begin{array}{c}-1.72 \\
(-11.66)\end{array}$ & $\begin{array}{c}-0.51 \\
(-7.28)\end{array}$ & $\begin{array}{c}0.39 \\
(3.11)\end{array}$ & $\begin{array}{c}-0.83 \\
(-3.75)\end{array}$ & $\begin{array}{c}-0.74 \\
(-3.41)\end{array}$ & $\begin{array}{c}-0.70 \\
(-3.22)\end{array}$ & $\begin{array}{c}-3.21 \\
(-17.22)\end{array}$ & $\begin{array}{c}2.38 \\
(12.91)\end{array}$ & -0.85 \\
\hline & $C S$ & -3.39 & -3.38 & & & 0.01 & 0.01 & -0.09 & -0.05 & & 3.22 & 0.025 \\
\hline & CS & $(-14.59)$ & $(-12.11)$ & & & $(0.11)$ & $(0.11)$ & $(-0.66)$ & $(-0.37)$ & & (17.74) & \\
\hline & TS-CS & & & & & 0.37 & -0.84 & -0.65 & -0.65 & & & \\
\hline \multirow{6}{*}{$\begin{array}{c}\mathrm{DN} / \mathrm{UP} \\
(\mathrm{N}=105)\end{array}$} & & 5.38 & 4.51 & 1.04 & 3.03 & -0.86 & $\begin{array}{l}(-0.04) \\
-2.85\end{array}$ & $\frac{(-5.40)}{-2.97}$ & $\frac{(-3.20)}{-2.90}$ & 4.14 & -700 & -169 \\
\hline & TS & $\begin{array}{c}5.50 \\
(12.11)\end{array}$ & $(14.51)$ & $\begin{array}{l}1.04 \\
(8.11)\end{array}$ & $\begin{array}{l}5.03 \\
(9.31)\end{array}$ & $\begin{array}{l}-0.00 \\
(-2.72)\end{array}$ & $(-5.00)$ & $(-5.15)$ & $(-5.12)$ & $\begin{array}{c}4.14 \\
(13.90)\end{array}$ & $(-8.91)$ & \\
\hline & & 5.70 & 4.58 & & & -1.12 & -1.12 & -0.99 & -0.94 & & -5.27 & -1.19 \\
\hline & CS & $(11.32)$ & (14.36) & & & $(-3.53)$ & $(-3.53)$ & $(-3.17)$ & $(-2.98)$ & & $(-10.07)$ & \\
\hline & TS-CS & & & & & 0.26 & -1.73 & -1.98 & -1.96 & & & \\
\hline & & & & & & $(2.49)$ & $(-5.42)$ & $(-5.96)$ & $(-5.96)$ & & & \\
\hline \multirow{5}{*}{$\begin{array}{l}\mathrm{DN} / \mathrm{DN} \\
(\mathrm{N}=80)\end{array}$} & TS & $\begin{array}{c}-5.80 \\
(-11.01)\end{array}$ & $\begin{array}{c}-4.42 \\
(-9.57)\end{array}$ & $\begin{array}{c}-0.82 \\
(-5.73)\end{array}$ & $\begin{array}{c}-2.64 \\
(-9.21)\end{array}$ & $\begin{array}{c}1.37 \\
(5.39)\end{array}$ & $\begin{array}{c}3.19 \\
(7.78)\end{array}$ & $\begin{array}{c}3.31 \\
(7.98)\end{array}$ & $\begin{array}{c}3.38 \\
(7.99)\end{array}$ & $\begin{array}{c}-4.60 \\
(-12.07)\end{array}$ & $\begin{array}{c}7.80 \\
(11.32)\end{array}$ & 3.01 \\
\hline & & -5.98 & -4.40 & & & 1.57 & 1.57 & 1.43 & 1.50 & & 6.17 & 2.70 \\
\hline & CS & $(-11.17)$ & $(-9.73)$ & & & $(6.97)$ & $(6.97)$ & $(6.44)$ & $(6.27)$ & & (12.35) & \\
\hline & TS_CS & & & & & -0.20 & 1.62 & 1.88 & 1.89 & & & \\
\hline & & & & & & $(-2.51)$ & (6.04) & $(6.72)$ & (6.79) & & & \\
\hline
\end{tabular}

